www.jmscr.igmpublication.org

Index Copernicus Value: 79.54

ISSN (e)-2347-176x ISSN (p) 2455-0450

crossrefDOI: https://dx.doi.org/10.18535/jmscr/v7i3.118

\title{
Effect of intravenous dexmedetomidine and midazolam on spinal anaesthesia with $0.5 \%$ hyperbaric bupivacaine in TURP
}

\author{
Authors \\ Dr Khageswar Raut, Assoc Prof., Dr Debasish Swain*, Assoc. Prof., \\ Dr Sidharth Sraban Routray, Assoc. Prof.
}

Department of Anesthesiology and Critical Care, SCB Medical College \& Hospital, Cuttack, Odisha, India *Corresponding Author

Dr Debasish Swain

Email:drkitusraban@gmail.com

\begin{abstract}
Aim: The study was done to evaluate the effects of intravenous administration of dexmedetomidine and midazolam on spinal anaesthesia with $0.5 \%$ hyperbaric bupivacaine in transurethral resection of prostate (TURP).
\end{abstract}

Methods: 75 patients of ASA grade I and II posted for elective transurethral resection of prostate surgeries were included in the study and randomly allocated into three groups. All three groups received $3 \mathrm{ml}$ of intrathecal $0.5 \%$ bupivacaine heavy, followed by infusion of study drug. Group D received intravenous dexmedetomidine $0.5 \mathrm{mcg} / \mathrm{kg}$ over $10 \mathrm{~min}$, Group $M$ received infusion of Midazolam and Group NS received infusion of same volume of normal saline as placebo. Duration of analgesia, time to 1st analgesia request, VAS score, hemodynamics and side effects were recorded and analyzed.

Results: The prolongation in duration of analgesia in dexmedetomidine group was statistically significant in comparison to other groups. Time to 1 st analgesia request was delayed in group D compared to other groups which was statistically significant. hemodynamic stability was well maintained in dexmedetomidine group.

Conclusion: Intravenous dexmedetomidine is not only prolong the duration of spinal analgesia but also maintain hemodynamic stability in TURP surgery.

Keywords: dexmedetomidine, spinal anaesthesia, hyperbaric bupivacaine, TURP.

\section{Introduction}

Subarachnoid block is one of the most frequently used anaesthetic techniques. Spinal anaesthesia is distinguished by its ease to performance with a definite end point, rapid onset of action, excellent anaesthetic efficacy and motor blockade. Spinal analgesia is a well-known technique used in lower abdominal, urological, and lower extremity procedures and a variety of agents like epinephrine, phenylephrine,

adenosine, magnesium sulfate and clonidine, have been used as adjuncts to local anesthesia for prolonging the duration of spinal analgesia. The addition of adjuvants to local anesthetics gained an extensive reputation due to the belief that they might prolong spinal anaesthesia, decrease the dosage of local anaesthetic, delayed-onset of postoperative pain and reduced analgesic requirements. 
Dexmedetomidine is a highly selective $\alpha 2$ adrenoreceptor agonist. ${ }^{1}$ It has been used for premedication and as an adjunct to general anaesthesia, as it provides preoperative sedation, analgesia and hemodynamic stability and reduces requirements for intraoperative inhalational agents and prolongs postoperative analgesics. ${ }^{2}$ Also, it has been used safely as premedication or as a sedative agent in patients undergoing surgical procedures under regional anaesthesia. ${ }^{3}$ Although a synergistic interaction between intrathecal dexmedetomidine and local anaesthetics has been observed in previous studies, there are few clinical data regarding the effect of intravenous dexmedetomidine premedication on the duration of sensory and motor block during spinal anaesthesia. ${ }^{4}$ Hence this study was done to assess the effects of intravenous dexmedetomidine premedication on spinal block duration as well as on sedation and postoperative analgesia in patients undergoing TURP surgeries.

\section{Methods}

75 patients undergoing elective operative procedures under spinal anaesthesia for TURP in SCB Medical College\& Hospital were included in the study during the period September 2015 to October 2017. The study was approved by Hospital Ethical Committee. Patients were allocated into one of the three groups, 25 patients each, based on a computer generated random numbers table:

- Group M: Midazolam group

- Group D: Dexmedetomidine group

- Group NS: Normal saline group

Exclusion criteria

- Patient refusal

- Coagulopathy

- Hemodynamically unstable patients

- Allergy to any of the study drugs

After intravenous insertion of an $18-\mathrm{G}$ catheter in the operating room, all patients received $500 \mathrm{ml}$ of lactated Ringer's solution intravascular volume loading before spinal anaesthesia. Monitors included electrocardiography, non-invasive blood pressure measurement, pulse oximetry to measure peripheral oxygen saturation (SpO2). All the patient were placed in the lateral position and dural puncture was performed at the L3-4 interspace using a standard midline approach with a 25-G Quincke needle. Bupivacaine $0.5 \% 3 \mathrm{ml}$ was injected intrathecally, and the patients was received oxygen $4 \mathrm{~L} / \mathrm{min}$ via a facemask throughout the procedure. IV infusion of dexmedetomidine started at a $1 \mu \mathrm{g} / \mathrm{kg}$ loading dose over 10 minutes, followed by a continuous infusion $(0.5 \mu \mathrm{g} / \mathrm{kg} / \mathrm{hr})$ in group D. Intravenous midazolam was administered in Group M (0.05 $\mathrm{mg} / \mathrm{kg}$ ) loading dose, followed by a continuous infusion $(0.02 \mathrm{mg} / \mathrm{kg} / \mathrm{hr}$.) Saline were given IV in group NS.

Both the patient and the anaesthesiologist was blinded to the treatment group, and all recordings was performed by an anaesthesiologist blinded to group allocation. Sensory blockade was assessed using pin prick in the mid-axillary line. Recovery time for sensory blockade was defined as two dermatome regression of anaesthesia from the maximum level. Motor block was assessed immediately after sensory block assessment using a Modified Bromage Scale :1= no paralysis; $2=$ unable to raise extended leg; 3 = unable to flex knee; $4=$ unable to flex ankle. Motor block duration was measured as the time for return to Modified Bromage Scale. Sensory and motor block was assessed every $2 \mathrm{~min}$ for the first 10 min and thereafter every $10 \mathrm{~min}$ during surgery and postoperatively.The highest sensory block level and recovery time of both sensory and motor block was recorded. Postoperative pain was assessed using the visual analogue scale (VAS),0 $=$ no pain; $10=$ worst possible pain. In addition, the overall 24-hr pain VAS was evaluated by the overall pain impression of the patient for $24 \mathrm{hr}$ postoperatively. Patients with a VAS score of 3 or more was received diclofenac $75 \mathrm{mg}$ intramuscularly. The time for the first request for postoperative analgesia and the number of patients who required supplemental analgesia were recorded. The Ramsay sedation score was used for 
sedation score: $1=$ anxious and agitated; $2=$ cooperative and tranquil; $3=$ drowsy but responsive to command; 4 =asleep but responsive to a glabellar tap; $5=$ asleep with a sluggish response to tactile stimulation; $6=$ asleep and no response.

The score was re-evaluated every $10 \mathrm{~min}$ for up to $120 \mathrm{~min}$. Excessive sedation was defined as a score greater than 4/6. Heart rate (HR), mean blood pressure (MAP), oxygen saturation ( $\mathrm{SpO} 2)$, and respiratory rate (RR) was recorded before premedication, 2 min after end of premedication, immediately before and after dural puncture, and every 5 min for 120 min after spinal anaesthesia. Hypotension (defined by a decrease in MAP below $20 \%$ of baseline or systolic pressure- 90 $\mathrm{mmHg}$ ) was treated with intravenous ephedrine 5 mg and additional lactated Ringer's solution (200 $\mathrm{mL}$ over a 5 min period). Bradycardia (HR-50 beats/min) was treated with intravenous atropine $0.6 \mathrm{mg}$. The occurrence of any complication in the preoperative and postoperative periods will be noted, particularly in relation to respiratory or cardiovascular problems, nausea or vomiting, and headache. Statistical analysis: The data will be analysed statistically using SPSS version 24 (spssInc., Chicago, IL, USA). The ANOVA test will be used to assess differences among the 3 groups with respect to non-parametric variables. If this will reveal significant differences, the BONFERRONI test will be used to analyse differences between groups in pairs. Categorical data will be analysed using the chi square test. A ' $p$ ' values $<0.05$ will be considered to indicate statistical significance

\section{Results}

75 ASA I \& II patients admitted in SCB MCH between September 2015 to October 2017, who had satisfied the criteria of inclusion and exclusion were included in the study. The written consent was taken from the patients. There was no statistical difference in three groups regarding demographic parameters.(table-1)

Table 1: Demographic parameters

\begin{tabular}{|l|c|c|c|c|}
\hline Parameters & $\begin{array}{c}\text { Group D } \\
(\mathrm{n}=25) \\
(\text { mean } \pm \mathrm{sd})\end{array}$ & $\begin{array}{c}\text { Group M } \\
(\mathrm{n}=25) \\
(\text { mean } \pm \mathrm{sd})\end{array}$ & $\begin{array}{c}\text { Group NS } \\
(\mathrm{n}=25) \\
(\text { mean } \pm \mathrm{sd})\end{array}$ & P-value \\
\hline Age $(\mathrm{yrs})$ & $54.72 \pm 3.18$ & $55.15 \pm 2.97$ & $5525 \pm 2.53$ & .926 \\
\hline Weight $(\mathrm{kg})$ & $78.9 \pm 9.4$ & $80.8 \pm 5.24$ & $78.8 \pm 9.4$ & .970 \\
\hline Height $(\mathrm{cms})$ & $169.6 \pm 5.85$ & $169.2 \pm 6.15$ & $169.6 \pm 5.9$ & .600 \\
\hline
\end{tabular}

The mean and standard deviation of intraoperative mean arterial pressure among the three groups were compared. There is no statistical significance difference among 3 groups. The Mean arterial pressure between the three groups at 15,30,45, 90, 105, 120 minutes were compared by ANOVA yields $\mathrm{P}$ value of $<0.05$ (Table 3 -A) , but the pair wise significance analysis by BONFERONI test revealed no statistically significant result between Dexmedetomidine and Midazolam groups.(Fig 1)

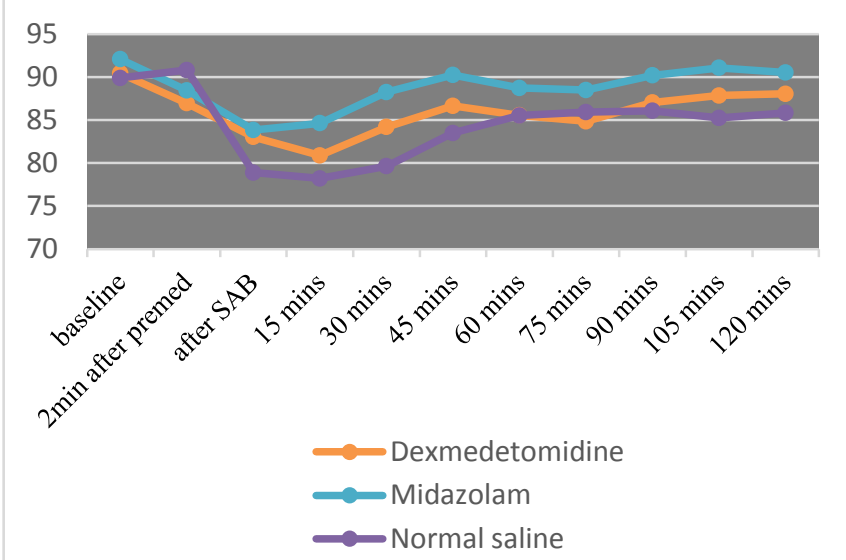

Figure 1: Changes in MAP

The mean and Standard deviation of intra operative heart rate were compared among three groups D, M, NS. The heart rate between the three 


\section{JMSCR Vol||07||Issue||03||Page 644-649||March}

groups at 5, 45, 120 mins were compared by ANOVA yields $\mathrm{P}$ value of $<0.05$ (Table $4-\mathrm{A}$ ), but the pair wise significance analysis by BONFERONI test revealed no statistically significant result between Dexmedetomidine and midazolam groups.(Fig 2)

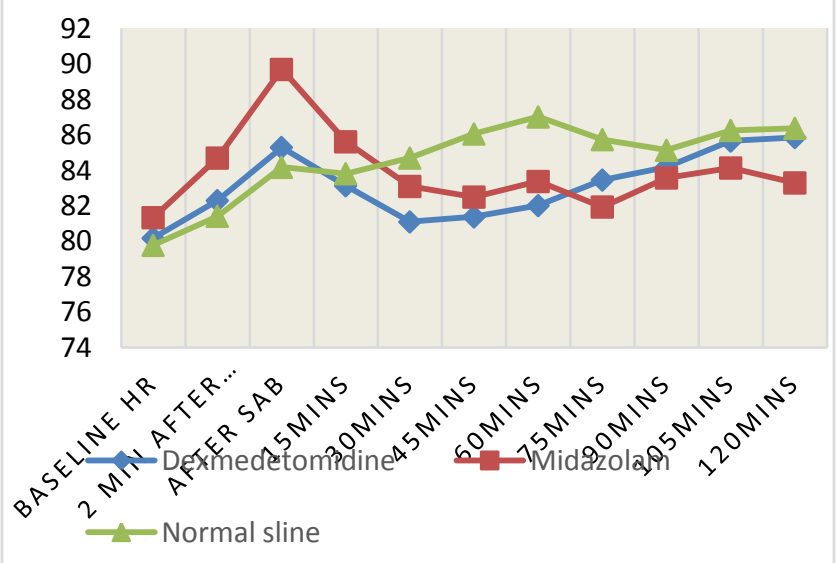

Figure 2: Changes in HR

The mean and standard deviation of time taken for highest sensory level, time for two segment regression, time to reach Bromage 3 to Bromage 1 for the group D, group $M$, group NS were analysed. ANOVA was used to analyse the mean difference of time to reach highest sensory level, time for two-segment regression and time to reach from Bromage 3 to Bromage 1 between three groups. The results displayed that there is a significant difference in time to reach highest sensory levels, two segment regression among the three groups. The pair wise comparison of groups showed that group D is significantly different from other two groups for two segment regression and Highest sensory level. The time taken for HSL in group D is lesser than group $\mathrm{M}$ and group NS. The time taken for $2 \mathrm{DR}$ is more in group Dexmedetomidine in comparison to Midazolam and normal saline group. The motor block (Bromage 3 to Bromage 1) among the three groups are not statistically significant. (Fig 3)

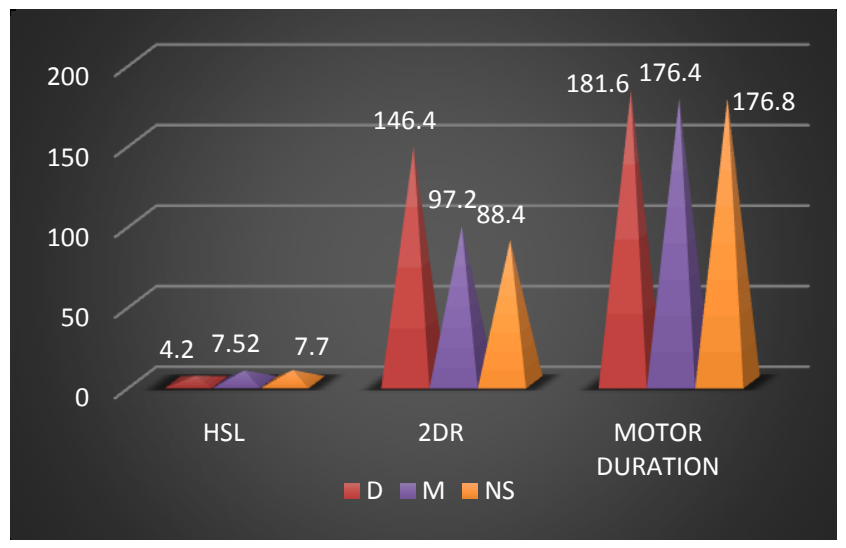

Figure 3: Changes in HSL, 2DR, Motor duration

The mean and Standard deviation of visual analogue score and time for analgesia among three groups were compared. ANOVA was done to determine whether there is a significant difference in the visual analogue scale and time for analgesia among the three groups D, M, NS. The results obtained from the analysis shows that there is a significant difference with respect to VAS. It is lesser in Dexmedetomidine group compared to midazolam and normal saline group $(\mathrm{p}<0.05)$. (Fig 4)

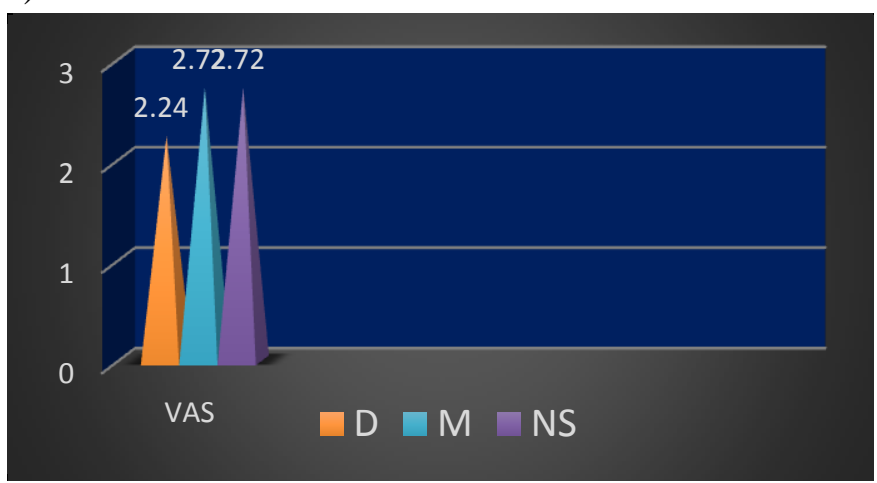

Figure 4: Changes in VAS

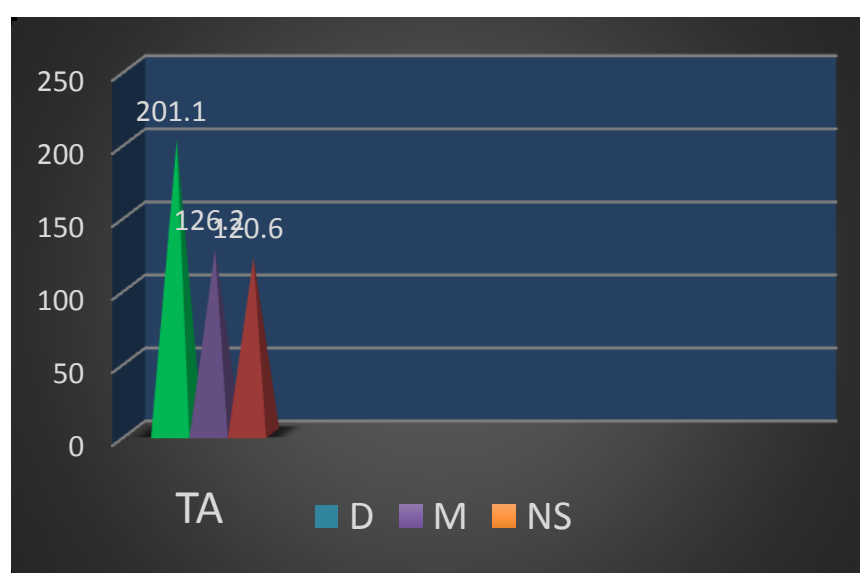

Figure 5: Time to rescue analgesia requirement 
Time to first request for postoperative analgesia was later in the Dexmedetomidine group than in the Midazolam and Normal saline groups $(\mathrm{P}<0.05)$. Fewer patients in the Dexmedetomidine group required an analgesic (Diclofenac $\mathrm{Na}$ ) during the first $24 \mathrm{hr}$ after spinal block than in the midazolam $(\mathrm{P}<0.05)$ and saline $(\mathrm{P}<0.05)$ groups (Fig 5,6).

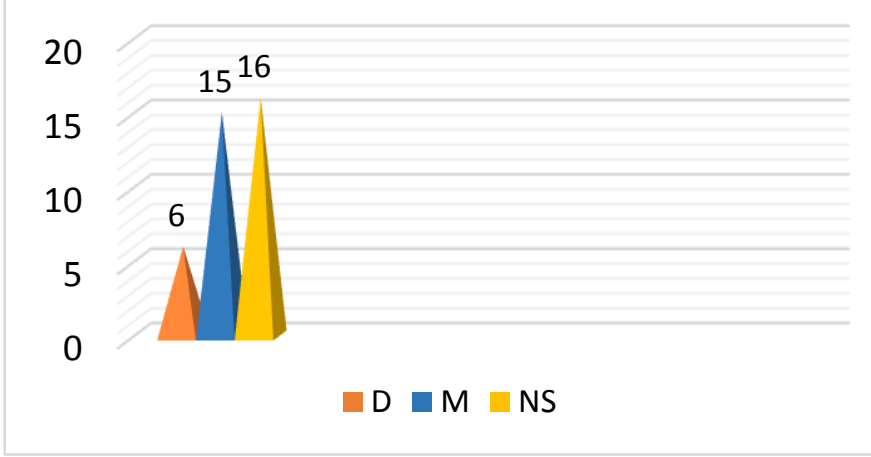

Figure 6: No of patients requiring rescue analgesia.

Table 2: Comparison of side effects

\begin{tabular}{|l|c|c|c|c|}
\hline Parameter & $\begin{array}{c}\text { Group D } \\
(\mathrm{n}=25)\end{array}$ & Group M(n=25) & Group S(n=25) & P value \\
\hline Hypotension & $3(12 \%)$ & 0 & $5(20 \%)$ & 0.070 \\
\hline Bradycardia & $2(8 \%)$ & 0 & $1(4 \%)$ & 0.353 \\
\hline Sedation(5/6) & $2(8 \%)$ & $5(20 \%)$ & 0 & 0.050 \\
\hline
\end{tabular}

The incidence of hypotension was found higher in group NS than in group M \& D. A Chi-square test analysed that there is no significant difference between the three groups in the occurrence of hypotension as the significance level is greater than 0.05. (Table 9) Excessive sedation (Ramsay sedation score of 5) was observed in two patients of the Dexmedetomidine group and in five patients of the midazolam group. Bradycardia was found to be $8 \%$ in Group D, where group Midazolam reported no such cases. A Chi-square test determined that there is no significant difference between the three groups in the incidence of bradycardia as the significance level is greater than 0.05. Side effects such as dyspnoea, shivering, nausea, headache, TNS and backache were not found in any groups (Table 2).

\section{Discussion}

$\alpha$-2-adrenoceptor agonists are being commonly used for their sedative, analgesic, sympatholytic, anaesthetic-sparing and favourable haemodynamic properties. Dexmedetomidine, is an agonist having a relatively high $\alpha_{2} / \alpha_{1}$-activity ratio (1620:1) as compared to clonidine (220:1). It has no respiratory depressant action, and provides conscious sedation making it therapeutically a useful and safe adjunct. ${ }^{6}$ In the spinal cord, activation of both $\alpha_{2} \mathrm{C}$ and $\alpha_{2}$-a adrenoceptors, located in superficial dorsal horn neurons especially the lamina II. Postsynaptic activation of central $\alpha_{2}$ adrenoceptors, results in a fall in blood pressure and heart rate, which attenuate the surgical stress. ${ }^{7}$ In our study, all three groups were comparable with respect to demographic profile, duration and type of surgery. The primary outcome of present study was increased duration of both sensory and motor block along with prolonged postoperative analgesia following addition of Dexmedetomidine to intrathecal hyperbaric Bupivacaine.In the present study, there was prolonged duration of sensory and motor block in Dexmedetomidine group. Our results agrees with studies done by, Al-Mustafa et al., and Shukla et al. ${ }^{9}$ The time for 2 segment regression was considerably prolonged in Group $\mathrm{D}$ when compared to group $\mathrm{M}$ and group $\mathrm{C}$. This is similar with the findings of Sheriff A Abdelhamid et al., ${ }^{10}$ Hala E A et al., ${ }^{11}$ Kanazi et al., ${ }^{12}$ and Gupta et al. ${ }^{13}$ In our study, there was significant reduction in the VAS scores of the patients receiving Dexmedetomidine as compared to Midazolam and saline. Dexmedetomidine when added to intrathecal bupivacaine 
significantly decreased the requirement of rescue analgesia in the postoperative period and delayed the requirement of $1^{\text {st }}$ rescue analgesic request. This is in agreement with study by Gupta $\mathrm{K} .{ }^{14}$ Cardiovascular profile in our patients was stable in the intraoperative and postoperative period in group D compared to other groups.

\section{Conclusion}

Intravenous dexmedetomidine provided better spinal block quality by prolonging the sensory block when compared to midazolam. Hemodynamics was stable with Dexmedetomidine group as compared to Midazolam group in TURP surgery.

\section{References}

1. Memi D, Turan A, Karamanlioğlu B, Pamukçu Z, Kurt I. Adding dexmedetomidine to lidocaine for intravenous regional anesthesia. Anesth Analg. 2004;98:835-40.

2. Reddy VS, Shaik NA, Donthu B, Reddy Sannala VK, Jangam V. Intravenous dexmedetomidine versus clonidine for prolongation of bupivacaine spinal anesthesia and analgesia: A randomized double-blind study. J Anaesthesiol Clin Pharmacol. 2013;29:34.

3. Gerlach AT, Dasta JF. Dexmedetomidine: An updated review. Ann Pharmacother. 2007; 41:245-52.

4. Harsoor S, Rani DD, Yalamuru B, Sudheesh $\mathrm{K}$, Nethra S. Effect of supplementation of low dose intravenous dexmedetomidine on characteristics of spinal anaesthesia with hyperbaric bupivacaine. Indian J Anaesth. 2013;57:265-9.

5. Hall JE, Uhrich TD, Barney JA, Arain SR, Ebert TJ. Sedative, amnestic, and analgesic properties of small-dose dexmedetomidine infusions. Anesth Analg. 2000;90:699-705.

6. Kaya FN, Yavascaoglu B, Turker G, Yildirim A, Gurbet A, Mogol EB, et al. Intravenous dexmedetomidine, but not midazolam, prolongs bupivacaine spinal anesthesia. Can J Anaesth. 2010;57:39-45.

7. Joana A, Flávio R. Dexmedetomidine: current role in anaesthesia and intensive care. Rev Bras Anestesiol. 2012;62(1):125-33.

8. Al-Mustafa MM, Abu-Halaweh SA, Aloweidi AS, Murshidi MM, Ammari BA, Awwad $\mathrm{ZM}$, et al. Effect of dexmedetomidine added to spinal bupivacaine for urological procedures. Saudi Med J. 2009;30(3):36570.

9. Shukla D, Verma A, Agarwal A, et al. Comparative study of intrathecal dexmedetomidine with intrathecal magnesium sulfate used as adjuvants to bupivacaine. Journal of Anaesthesiology, Clinical Pharmacology. 2011;27(4):495-99.

10. Abdelhamid SA, El-lakany MH. Intrathecal dexmedetomidine: Useful or not? J Anaesth Clin Res. 2013;4:351..

11. Hala E A Eid, Shafie M, Youssef H. Dose related prolongation of hyperbaric bupivacaine spinal anaesthesia by Dexmedetomidine. Ain Shams Journal of Anaesthesiology. 2011;4(2):83-95.

12. Kanazi GE, Aouad MT, Jabbour-Khoury SI, et al. Effect of low-dose dexmedetomidine or clonidine on the characteristics of bupivacaine spinal block. Acta Anaesthesiologica Scandinavica. 2006;50:222-27.

13. Gupta R, Verma R, Bogra J, et al. A comparative study of intrathecal dexmedetomidine and fentanyl as adjuvants to bupivacaine. J Anaesthesiol Clin Pharmacol. 2011;27:339-43.

14. Gupta K, Tiwari V, Gupta PK, Pandey MN, Agarwal S, Arora A. Prolongation of subarachnoid block by intravenous dexmedetomidine for sub umbilical surgical procedures: A prospective control study. Anesth Essays Res. 2014;8(2):175-8. 